\title{
Por onde anda a comunidade de Sistemas Colaborativos?
}

\author{
Ana Cristina B Garcia \\ Universidade Federal do Estado \\ do Rio de Janeiro \\ Rio de Janeiro, Brasil \\ cristina.bicharra@uniriotec.br
}

\author{
Adriana S Vivacqua \\ Universidade Federal do \\ Rio de Janeiro \\ Rio de Janeiro, Brasil \\ avivacqua@dcc.ufrj.br \\ Marcos R S Borges \\ Universidade Federal do \\ Rio de Janeiro \\ Rio de Janeiro, Brasil \\ mborges@ppgi.ufrj.br
}

\author{
Vaninha Vieira \\ Universidade Federal da Bahia \\ Salvador, Brasil \\ vaninha@ufba.br
}

\begin{abstract}
Este artigo apresenta resultados de um levantamento feito com a comunidade brasileira de sistemas colaborativos sobre sua percepção quanto ao término do Simpósio Brasileiro em Sistemas Colaborativos e da Comissão Especial de Sistemas Colaborativos da SBC.
\end{abstract}

\section{Author Keywords}

Sistemas colaborativos; comunidade.

\section{ACM Classification Keywords}

H.5.m. Information interfaces and presentation (e.g., HCI): Miscellaneous.

\section{INTRODUÇÃO}

Na reunião da comunidade de sistemas colaborativos durante o Simpósio Brasileiro de Sistemas Colaborativos (SBSC), de 2017, realizado em São Paulo, foi decidido que não haveriam novas edições do evento, e que este seria absorvido pela comunidade de IHC. A inexistência de eventos implica também no fim da Comissão Especial de Sistemas Colaborativos (CESC) da SBC.

Acreditamos que existam outras estratégias possíveis para reavivar a comunidade antes de efetivamente encerrá-la. Para verificar essas estratégias, decidimos, com o aval da CESC, realizar um levantamento junto à comunidade brasileira de Sistemas Colaborativos, para saber a opinião dos pesquisadores da 'rea sobre o assunto, incluindo aqueles que não puderam estar presentes na reunião do SBSC 2017. O objetivo desse estudo foi mapear como pensam esses pesquisadores, e que possibilidades são percebidas para a

\footnotetext{
Permission to make digital or hard copies of all or part of this work for personal or classroom use is granted without fee provided that copies are not made or distributed for profit or commercial advantage and that copies bear this notice and the full citation on the first page. Copyrights for components of this work owned by others than the author(s) must be honored. Abstracting with credit is permitted. To copy otherwise, or republish, to post on servers or to redistribute to lists, requires prior specific permission and/or a fee. Copyright 2018 SBC.
}

IHC 2018, Anais Estendidos do XVII Simpósio Brasileiro sobre Fatores Humanos em Sistemas Computacionais Outubro 22-26, 2018, Belém, Brasil

Fórum de Integração e Discussão sobre Interação Humano-Computador e Sistemas Colaborativos (FID IHC-SC)
CESC, enquanto comunidade, bem como para evento(s) associados à mesma, que justificassem sua existência junto à SBC, ou mesmo a outras sociedades fora da Computação. Com esse levantamento, procuramos entender se a comunidade realmente se dissolveu, migrou ou se está apática, e se há como reanimá-la. Esse material serve como ponto de partida para uma reflexão do grupo.

Para isso, preparamos um questionário e solicitamos a todos que trabalham com temas relacionados a sistemas colaborativos (ainda que não seja sua principal área de pesquisa) a responderem. O questionário foi elaborado no SurveyMonkey (surveymonkey.com). O questionário foi composto de 19 questões, em sua maioria perguntas fechadas com a opção 'Outros (especifique)'. Também incluímos 2 questões abertas para obter percepções sobre a possível união da comunidade de sistemas colaborativos com outra área e obter sugestões.

O questionário foi disponibilizado durante aproximadamente 45 dias, no período de 14 de Maio a 25 de Junho de 2018. Um email com texto explicativo e finalidade da pesquisa foi enviado às listas da SBC, CESC, aos participantes do comitê de programa do SBSC 2017 (52 pessoas), e a pesquisadores que trabalham em temas relacionados à área, de conhecimento dos autores.

Foram obtidas, no total, 38 respostas ao questionário. As respostas vieram lentamente, mas encontramos com pessoas em congressos outros que comentaram não saber do questionário, o que indica que a estratégia de distribuição pode ter sido falha. Porém, acreditamos que, mesmo não obtendo respostas de todos os pesquisadores que, em algum momento, participaram da comunidade, o grupo de respondentes é representativo das pessoas que se importam com a comunidade de Sistemas Colaborativos, contemplando as 5 regiões brasileiras.

\section{DEMOGRAFIA DOS RESPONDENTES}

Foram 38 respondentes, dentre eles 30 professores/ pesquisadores, 7 alunos de pós-graduação e 1 profissional de mercado. Desses, 21 são homens e 17 mulheres. Apesar do 


\begin{tabular}{rcc} 
& Feminino & Masculino \\
\hline Sudeste & 9 & 9 \\
Nordeste & 5 & 6 \\
Sul & 2 & 2 \\
Norte & 1 & 1 \\
Centro Oeste & 0 & 1 \\
Internacional & 0 & 2
\end{tabular}

Tabela 1. Demografia dos respondentes.

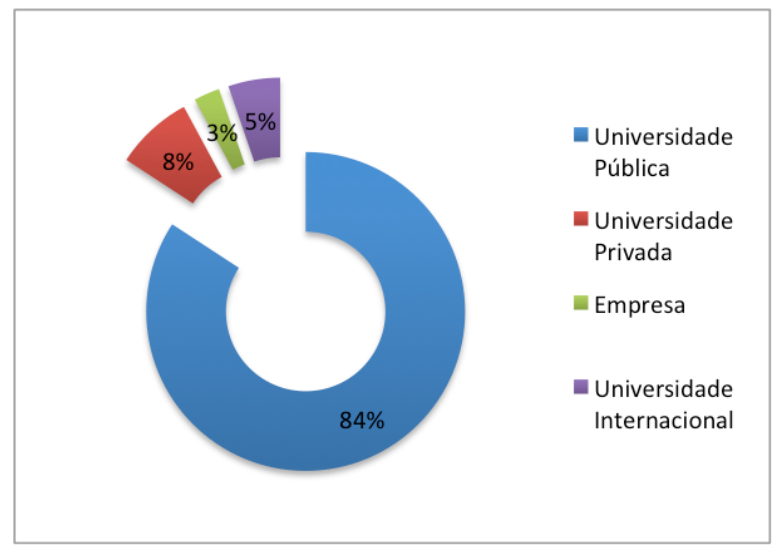

Figura 1. Vínculo profissional.

pequeno número de respondentes, os participantes estavam bem distribuídos pelo território nacional: 18 da região sudeste, 11 do nordeste, 4 do sul, 2 do norte, um do centrooeste e 2 vivendo do exterior, como mostrado na Tabela 1.

A grande maioria, cerca de 32 pessoas estão vinculadas ao serviço público, em especial universidade pública, como ilustrado na Figura 1. Ninguém faz pesquisa puramente quantitativa: $50 \%$ dos respondentes faz pesquisa puramente qualitativa e $50 \%$ faz quantitativa e qualitativa. A grande maioria faz pesquisa aplicada $(79 \%)$ e apenas $21 \%$ faz pesquisa teórica.

Calculamos o tamanho da comunidade considerando o número de respondentes (conexão direta) e o número de orientandos mencionados pelos participantes (conexão indireta). Como as opções de respostas sobre o número de alunos trabalhando na área de sistemas colaborativos eram faixas, consideramos o valor mínimo e máximo de cada faixa. Para faixas abertas, por exemplo acima de 5 alunos, o valor máximo foi considerado o valor mínimo + 1 (uma estimativa conservadora). Com isso chegamos que a comunidade de Sistemas Colaborativos, em 2018, tem um tamanho estimado de 126 a 195 integrantes. Portanto uma comunidade pequena, mas expressiva e espalhada pelo território nacional.

\section{ATUAÇÃO DA COMUNIDADE}

Houve pouca adesão da comunidade em 2017. Apenas $16 \%$ dos respondentes compareceram ao SBSC2017. Porém, desde 2013, apenas 29\% dos respondentes nunca

\begin{tabular}{rcc} 
& Nacional & Internacional \\
\hline Sist. Colaborativos & ---- & 26 \\
Int.Hum.Computador & 12 & 12 \\
Sist. Informação & 14 & 8 \\
WWW & 12 & 9
\end{tabular}

Tabela 2. Local de publicação de pesquisa.

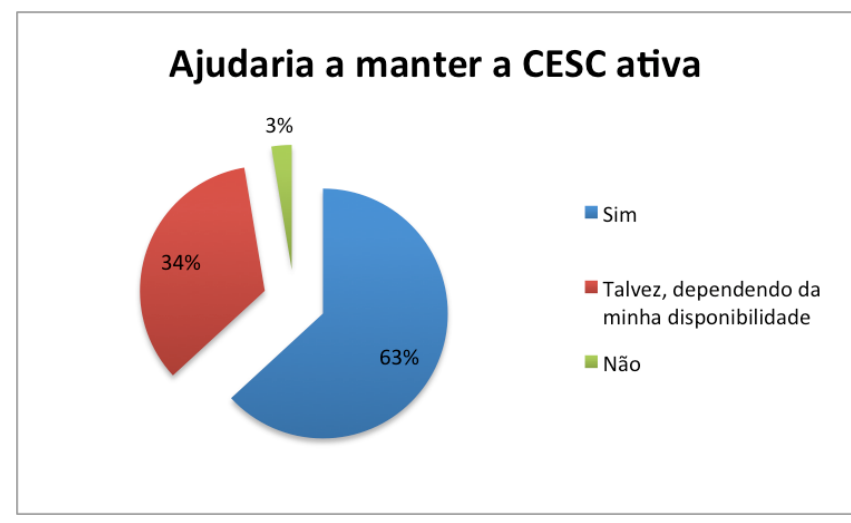

Figura 2. Compromisso para manutenção da CESC

participaram de um SBSC. $71 \%$ dos respondentes já publicaram nos anais do SBSC, $45 \%$ já participaram de comitê de programa e $32 \%$ já organizaram algum SBSC e $11 \%$ dos respondentes são novos na comunidade. Os respondentes informaram que publicam seus trabalhos em eventos nacionais e internacionais em outras áreas, como ilustrado na Tabela 2.

\section{E O FUTURO?}

Ao se confirmar o término da CESC e do SBSC, a comunidade restante irá se dissipar em múltiplos eventos, não havendo nenhum espaço agregador. Há uma percepção majoritária entre os respondentes de que o término da CESC é uma atitude precipitada.

Talvez a decisão de 2017 tenha exposto uma necessidade de revisão de rumos e objetivos, e criado esta oportunidade. Há ainda muito interesse em se manter a comunidade ativa. Apenas uma pessoa respondeu que não ajudaria a manter a CESC ativa, como ilustrado na Figura 2 (e este foi um respondente que julgou que não poderia ajudar por estar no exterior).

\section{Rumos e Possibilidades}

No questionário apresentamos algumas ideias iniciais de mudanças para a comunidade e o SBSC. Uma das propostas é relativa à periodicidade das conferências nacionais em sistemas colaborativos (SBSC), mostrado na Figura 3. A alteração de periodicidade refletiria talvez o tempo de maturação da pesquisa em sistemas colaborativos, e possivelmente mitigaria a baixa disponibilidade e adesão da comunidade, que teria mais tempo para organizar os eventos 


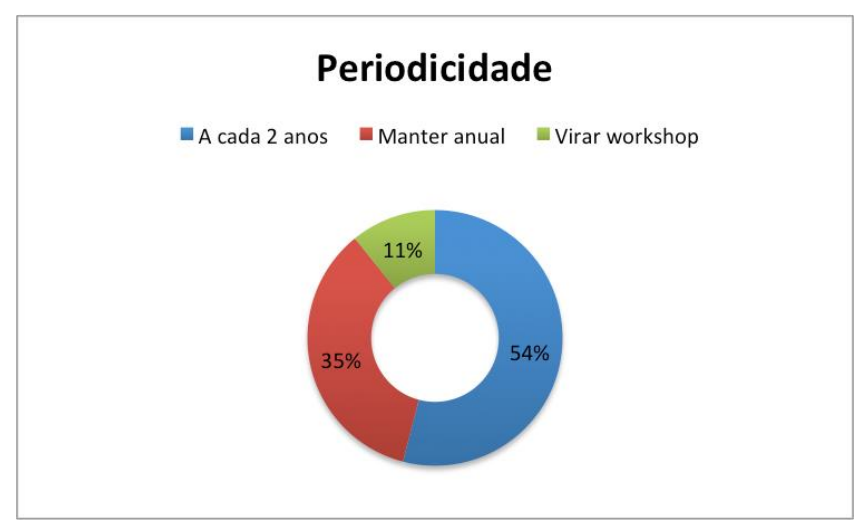

Figura 3. Proposta para periodicidade das conferências nacionais em Sistemas Colaborativos.

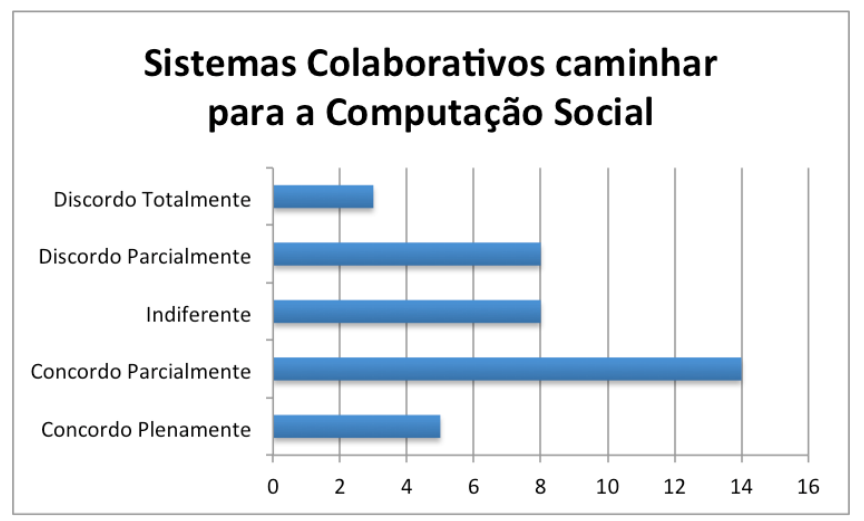

Figura 5. Sistemas Colaborativos como Computação Social.

e realizar as pesquisas. A opção de tornar-se um workshop junto a outras conferências não foi particularmente bem aceita.

Outra sugestão apresentada foi a aproximação de sistemas colaborativos com áreas afins, como ilustrado na Figura 4. As áreas que apareceram de forma mais proeminente foram as ciências sociais, comunicação e administração. Este pode ser um sinal que, a exemplo do que acontece na comunidade de sistemas colaborativos internacional, a área caminha para a computação social. Ao ser perguntada, a comunidade brasileira respondeu que vê com bons olhos mas foi cautelosa quanto a uma mudança de rumo na direção da computação social, como ilustrado na Figura 5.

As perguntas abertas trouxeram uma variedade de ideias de como podemos manter a comunidade. Também indica que a aproximação com outras áreas é bem-vinda, mas sem descaracterizar a nossa identidade. Analisamos e resumimos as sugestões enviadas, que foram bem diversificadas, como ilustrado no mapa de palavras da Figura 6. Há um senso comum que podemos nos aproximar de outras áreas sem fundir, que precisamos divulgar mais a área e até mesmo incluir nos currículos. Devemos fazer eventos co-localizados

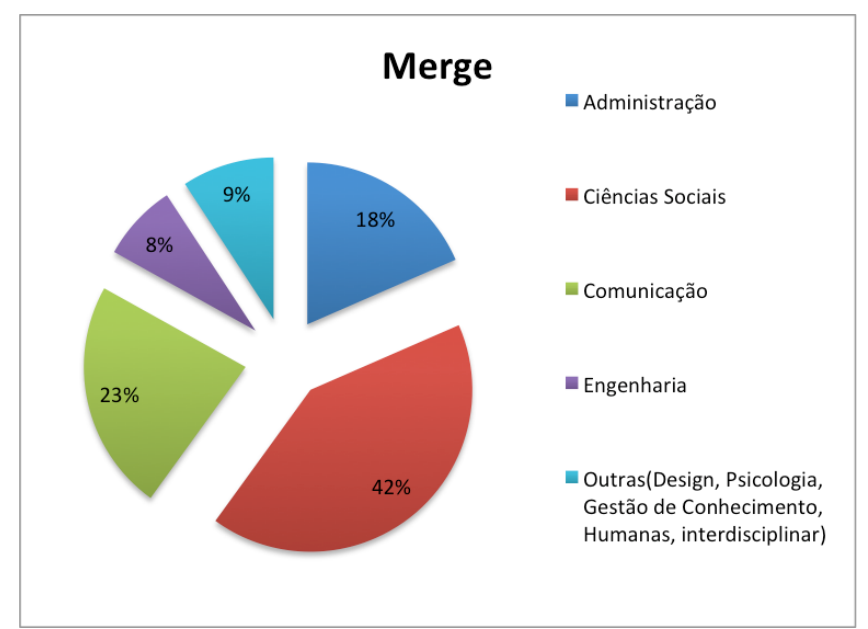

Figura 4. Áreas Afins.

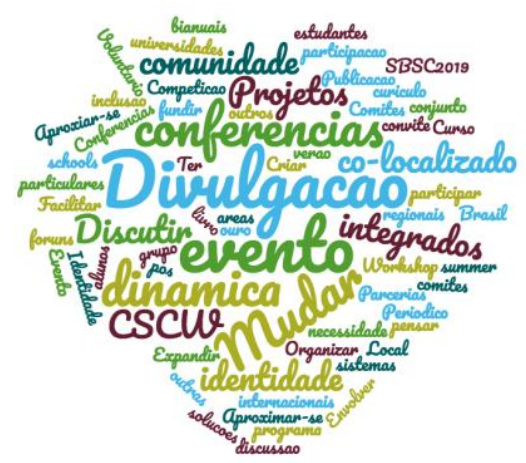

Figura 6. Sugestões para reavivar a comunidade.

e alguns acham que devemos ser um ramo dentro de eventos maiores. Os alunos devem ter mais espaço, devendo ser facilitada sua participação, seja pensando na localização dos eventos, nos custos para participação, ou na participação da conferência em si. Também há preocupação quanto à divulgação da área e o ensino/preparo dos alunos curricularmente ou com cursos de verão e mini-cursos nas conferências.

\section{CONCLUSÕES}

Neste artigo apresentamos um resumo executivo da opinião da comunidade sobre o fim do SBSC (e, consequente suspensão de atividades da comissão especial de sistemas colaborativos), que simboliza o término de um ponto de encontro e parceria. Resta a nós refletir individualmente e como grupo, se esgotamos as oportunidades como grupo ou se essa é uma grande oportunidade para a comunidade refletir, sair do ponto morto e decidir se novos rumos são desejáveis.

\section{AGRADECIMENTO}

Este artigo é um material para reflexão. Só foi possível pela colaboração das pessoas da comunidade que devotaram tempo para responder o questionário. 